\title{
Dual-Band Operation of a Microstrip Patch Antenna on a Duroid 5870 Substrate for Ku- and K-Bands
}

\author{
M. M. Islam, M. T. Islam, and M. R. I. Faruque \\ Institute of Space Science (ANGKASA), Universiti Kebangsaan Malaysia UKM, 43600 Bangi, Selangor D. E., Malaysia
}

Correspondence should be addressed to M. R. I. Faruque; rashedgen@yahoo.com

Received 1 October 2013; Accepted 14 November 2013

Academic Editors: Y.-C. Wang and J.-K. Xiao

Copyright (C) 2013 M. M. Islam et al. This is an open access article distributed under the Creative Commons Attribution License, which permits unrestricted use, distribution, and reproduction in any medium, provided the original work is properly cited.

The dual-band operation of a microstrip patch antenna on a Duroid 5870 substrate for $\mathrm{Ku}$ - and $\mathrm{K}$-bands is presented. The fabrication of the proposed antenna is performed with slots and a Duroid 5870 dielectric substrate and is excited by a $50 \Omega$ microstrip transmission line. A high-frequency structural simulator (HFSS) is used which is based on the finite element method (FEM) in this research. The measured impedance bandwidth $(2: 1 \mathrm{VSWR})$ achieved is $1.07 \mathrm{GHz}(15.93 \mathrm{GHz}-14.86 \mathrm{GHz})$ on the lower band and $0.94 \mathrm{GHz}(20.67-19.73 \mathrm{GHz})$ on the upper band. A stable omnidirectional radiation pattern is observed in the operating frequency band. The proposed prototype antenna behavior is discussed in terms of the comparisons of the measured and simulated results.

\section{Introduction}

The implementation of the microstrip patch antenna is a milestone in wireless communication systems and is continuing to fulfill the changing demands of the new generation of antenna technology. Microstrip patch antennas are widely used in wireless communication systems because they are low profile, of light weight, of low cost, of conformal design, and easy to fabricate and integrate. Many researchers have heavy interest in designing $\mathrm{Ku}$ - and $\mathrm{K}$-band antennas and still face a major challenge to implement these applications. The patch is the dominant figure of a microstrip antenna; the other components are the substrate and ground, which are the two sides of the patch [1]. Many dual-band antennas have been improved to face the rising demands of a modern portable wireless communication device that is capable of integrating more than one communication standard into a single system. For this reason, different types of antenna designs have been proposed [2-14].

A dual polarized microstrip patch antenna has been proposed for $\mathrm{Ku}$-band applications with dimensions of $15 \mathrm{~mm} \times 15 \mathrm{~mm}$, and such an antenna has achieved a $950 \mathrm{MHz}$ bandwidth with a maximum gain of $7.6 \mathrm{~dB}$, as noted in [15]. In [16], a multiband patch antenna was designed for $\mathrm{Ku}-$ and K-band applications with dimensions of $8 \mathrm{~mm} \times 10 \mathrm{~mm}$, a bandwidth of $760 \mathrm{MHz}$, and a peak gain of $4.5 \mathrm{~dB}$. In [17], a
Ku-band patch antenna using notches and slit was proposed, whose dimensions are $7.6 \mathrm{~mm} \times 10 \mathrm{~mm}$, with a substrate thickness of $0.8 \mathrm{~mm}$; Teflon is used as the dielectric substrate material, and the antenna obtained a maximum bandwidth of $600 \mathrm{MHz}$. In [18], a dual-band compact microstrip antenna was proposed for $\mathrm{Ku}$-band applications using three pairs of thin slits from the sides of a rectangular patch, whose dimensions are $9.5 \mathrm{~mm} \times 10 \mathrm{~mm}$; Rogers RT/Duroid 5880 is used as the dielectric substrate material, with a substrate thickness of $0.254 \mathrm{~mm}$; the antenna obtained a maximum bandwidth of $90 \mathrm{MHz}$. In [19], a dual-frequency triangular slotted microstrip patch antenna was proposed for $\mathrm{Ku}$-band applications, where the patch dimensions are $8.5 \mathrm{~mm} \times$ $7.96 \mathrm{~mm} \times 1.905 \mathrm{~mm}$; the substrate thickness is $1.905 \mathrm{~mm}$ (Rogers RT/Duroid 6010 is used as the dielectric substrate material), and the maximum bandwidth is $576 \mathrm{MHz}$. In all of the previous proposed antenna designs, narrow bandwidth was achieved for Ku-band applications.

A printed double-T monopole antenna was proposed in [20]. In [21], a compact dual-band microstrip antenna for Ku-band applications was proposed, whose dimensions are $9.50 \mathrm{~mm} \times 10 \mathrm{~mm} \times 0.254 \mathrm{~mm}$ and which achieved a return loss of $-23.83 \mathrm{~dB}$ at $12.54 \mathrm{GHz}$ and -14.04 at $14.15 \mathrm{GHz}$, with a gain greater than $4 \mathrm{dBi}$. Comparatively, the proposed antenna has a limited return loss. A surface mount dual-loop antenna was proposed in [22]. A dual-band reduced-size PIFA 


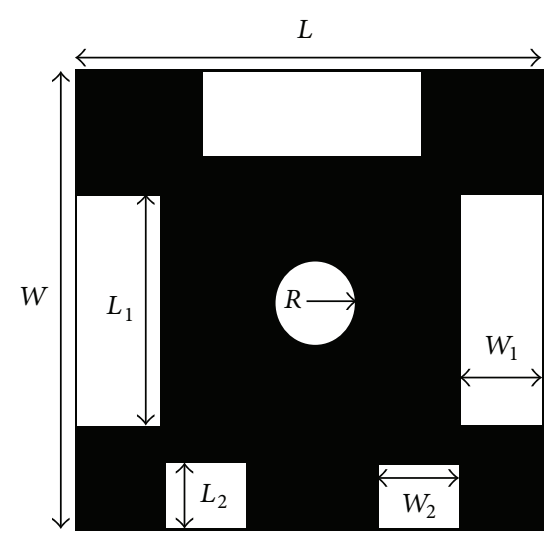

(a)

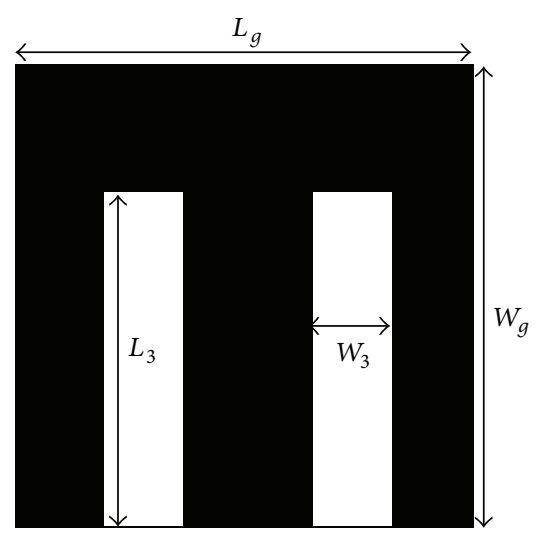

(b)

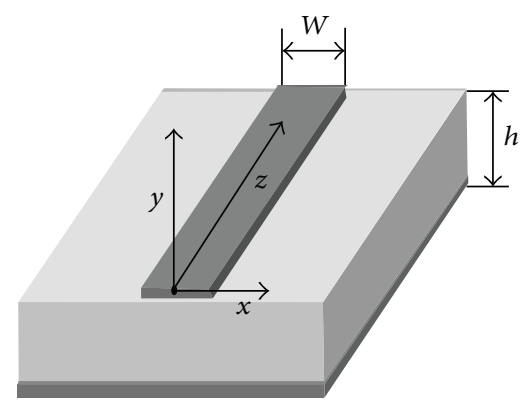

(c)

FIgURE 1: Proposed antenna: (a) top view, (b) bottom view, and (c) microstrip transmission line.

was proposed in [23]. These antennas provided dual-band features to cover the $2.4 / 5.2$ and $5.8 \mathrm{GHz}$ WLAN bands. The limitations of these antennas were that they could not deliver a uniform omnidirectional radiation pattern. A low-cost microstrip-fed dual-frequency printed dipole antenna was proposed for wireless communications in [24]. This antenna's size is large and its bandwidth is limited. In [25], a printed dual-band dipole antenna with U-slot arms was proposed for the $2.4 / 5.2 \mathrm{GHz}$ WLAN operation. The $370 \mathrm{MHz}$ bandwidth of that antenna is insufficient to cover the desired band. In [26], a dual broadband design of a rectangular slot antenna was proposed for 2.4 and $5 \mathrm{GHz}$ wireless communications. The antenna dimension is $75 \mathrm{~mm} \times 75 \mathrm{~mm}$, the substrate permittivity is 4.70 , and the thickness is $0.80 \mathrm{~mm}$. In [27], a dual-band WLAN dipole antenna using an internal matching circuit was proposed. The antenna dimensions are $12 \mathrm{~mm} \times 45 \mathrm{~mm}$ and FR4 is used as the dielectric substrate material to cover the desired bands.

In this study, a $20 \mathrm{~mm} \times 20 \mathrm{~mm}$ microstrip patch antenna was designed on a $1.575 \mathrm{~mm}$ thick Duroid 5870 substrate for use in $\mathrm{Ku}$ - and $\mathrm{K}$-band applications. A downlink frequency of $15.56 \mathrm{GHz}$ and an uplink frequency of $20.41 \mathrm{GHz}$, with return losses of $-32.56 \mathrm{~dB}$ and $-31.13 \mathrm{~dB}$, respectively, a peak gain of $3.90 \mathrm{~dB}$, and $98.5 \%$ average efficiency were achieved. The detailed design and simulation results for the proposed antenna were demonstrated later.

\section{Antenna Design}

The proposed antenna design with a microstrip transmission line is shown in Figure 1. The microstrip transmission line is one type of high-grade printed circuit fabric. This line comprises a track of copper or any other conductor with an insulating substrate. The other portion of the insulating substrate contains a backbone that is made of a similar conductor. The antenna is comprised of six conducting slots on the patch and two on the ground. A circular slot and five rectangular slots are on the patch, and two rectangular slots are on the ground of the proposed antenna. The design procedure begins with the radiating patch with the substrate, the ground plane, and a feed line. The antenna is printed on a
$1.575 \mathrm{~mm}$ thick Duroid 5870 substrate material that exhibits a relative permittivity of 2.33 , a relative permeability of 1 , and a dielectric loss tangent of 0.0012. A circular and five rectangular slots are cut from the rectangular copper patch. Another two rectangular slots are also cut from the ground plane. Thus, the proposed slotted circle patch antenna is finally achieved. Here, the microstrip line is used to feed the signal into the proposed antenna.

The subminiature version A (SMA) $50 \Omega$ connector is used at the end of the antenna feeding line for the input RF signal. The proposed antenna prototype is shown in Figure 2. The antenna design and the dimensions were investigated by using the Ansoft HFSS software, which is based on the finite element method (FEM), and the optimal dimensions were finally determined as follows: $L=20 \mathrm{~mm}, L_{g}=20 \mathrm{~mm}, L_{1}=$ $8 \mathrm{~mm}, L_{2}=3 \mathrm{~mm}, L_{3}=16 \mathrm{~mm}, R=2 \mathrm{~mm}, W=20 \mathrm{~mm}$, $W_{g}=20 \mathrm{~mm}, W_{1}=4 \mathrm{~mm}, W_{2}=3 \mathrm{~mm}$, and $W_{3}=3 \mathrm{~mm}$.

There are different types of materials for an antenna substrate; for example, Duroid 5870 is a high-frequency laminate and PTFE (polytetrafluoroethylene) composite amplified using glass microfibers. To increase the advantages of fiber reinforcement for circuit applications and circuit producers, these microfibers have been used aimlessly. The dielectric constant of the Duroid 5870 substrate material is lower than that of other products, and it is suitable for higher-frequency bands, where dispersion and losses must be decreased because of the low dielectric loss. Due to the lack of extensive water absorption features, Duroid 5870 substrate is typically used in heavy moisture environments. The Duroid 5870 is simply cut, machined, and sheared to shape, and it is impervious to all reagents and solvents usually used in engraving printed circuit boards or plating holes and edges. Duroid 5870 has the lowest electrical loss of any amplified PTFE substrate material, lower absorption due to the fact that moisture is isotropic, and constant electrical characteristics over frequency. Duroid 5870 has been used in circuitry for commercial airline telephones, stripline and microstrip circuits, military radar systems, millimeter-wave applications, point-to-point digital radio antennas, and missile guidance systems. For these reasons, the Duroid 5870 substrate material was chosen for the proposed antenna design to achieve 


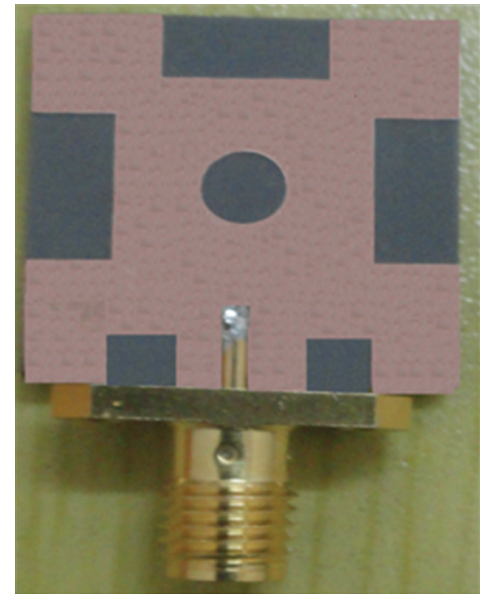

Patch

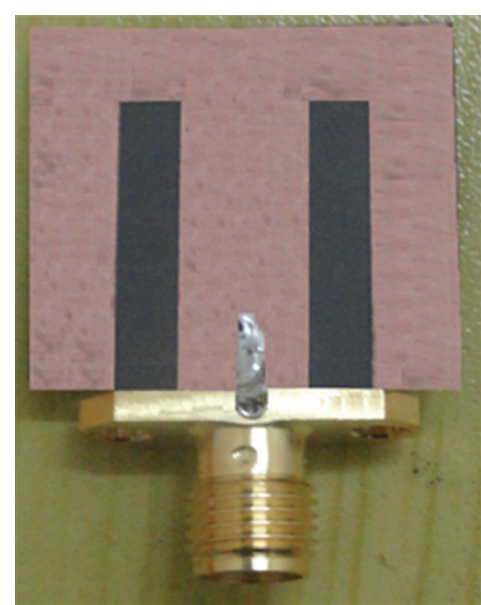

Ground

FIgURE 2: Prototype of the proposed antenna.

TABLE 1: Dielectric properties of different substrate materials.

\begin{tabular}{lcc}
\hline Material & Permittivity & Loss tangent \\
\hline Duroid 6010 & 10.2 & 0.0023 \\
$\mathrm{AL}_{2} \mathrm{O}_{3}$ & 9.8 & 0.0009 \\
$\mathrm{FR} 4$ & 4.66 & 0.020 \\
Duroid 5870 & 2.33 & 0.0023 \\
\hline
\end{tabular}

operation in the desired bands. The dielectric properties of the various substrate materials are listed in Table 1.

The length, width, VSWR, and return loss of the patch antenna can be calculated from (1), presented in [28], where $L$ and $W$ are the length and width of the patch, $c$ is the velocity of light, $\varepsilon_{r}$ is the dielectric constant of the substrate, $h$ is the thickness of the substrate, $f_{0}$ is the target centre frequency, $\varepsilon_{e}$ is the effective dielectric constant, and $\rho$ is the radiation coefficient:

$$
\begin{gathered}
W=\frac{c}{2 f_{0}} \sqrt{\frac{\varepsilon_{r}+1}{2}}, \\
L=\frac{c}{2 f_{0} \sqrt{\varepsilon_{r}}}-2 \Delta l \\
\varepsilon_{e}=\frac{1}{2}\left(\varepsilon_{r}+1\right)+\frac{1}{2}\left(\varepsilon_{r}-1\right) \sqrt{\left(1+\frac{10 h}{W}\right)}, \\
\Delta l=0.412 h \frac{\left(\varepsilon_{e}+0.3\right)[(W / h)+0.8]}{\left(\varepsilon_{e}-0.258\right)[(W / h)+0.8]}, \\
\operatorname{VSWR}=\frac{1+\rho}{1-\rho}, \\
\text { return loss }=-10 \log \left(\frac{1}{\rho^{2}}\right) .
\end{gathered}
$$

\section{Parametric Study}

A parametric study was performed to observe the effects of the proposed antenna parameters. The effects of the different parameters on the return loss were observed. In these simulations, the other parameters remained unchanged. Figure 3 shows the simulated return loss for different values of $L_{1}$. Two resonances were observed using the above values of $L_{1}$, one for the lower band and another for the upper band. The return loss of the lower band is low using $L_{1}=6 \mathrm{~mm}$ and $L_{1}=10 \mathrm{~mm} . L_{1}=8 \mathrm{~mm}$ can be considered the optimized value to achieve both the lower and upper bands. Figure 4 shows the simulated return loss for different values of $W_{1}$. Two resonances were found using the above values of $W_{1}$. The return loss is lower for $W_{1}=3 \mathrm{~mm}$ and $W_{1}=5 \mathrm{~mm}$ than for $W_{1}=4 \mathrm{~mm}$. $W_{1}=4 \mathrm{~mm}$ is the optimized value. Figure 5 shows the simulated return loss for different values of $R$. The radius of the circular slot, $R$, is an important parameter that plays a role in determining the desired frequency bands. The resonances are shifted using radii with values of $1 \mathrm{~mm}$, $3 \mathrm{~mm}$, and $4 \mathrm{~mm}$. By using $R=2 \mathrm{~mm}$, the desired dual-band operation was obtained, with improved bandwidth. Figure 6 shows the simulated return loss for different values of $W_{2}$. By using $W_{2}=2 \mathrm{~mm}$, the return loss is low on the lower band but high on the upper band. The return loss is low for both the upper and lower bands using $W_{2}=4 \mathrm{~mm}$. The optimized value is $W_{2}=3 \mathrm{~mm}$ for the appropriate characteristics on (1) both bands. Figure 7 shows the simulated return loss for different values of $L_{3}$. By using $L_{3}=12 \mathrm{~mm}$, the return loss is high on the lower band but low on the upper band. By using $L_{3}=20 \mathrm{~mm}$, the return loss is low on the lower band but high on the upper band. The optimized value is $L_{3}=16 \mathrm{~mm}$. The simulated return loss for different values of $W_{3}$ is shown in Figure 8. It is obvious that the optimized value of $W_{3}$ is $3 \mathrm{~mm}$, which is better than the other two values of $2 \mathrm{~mm}$ and $4 \mathrm{~mm}$. 


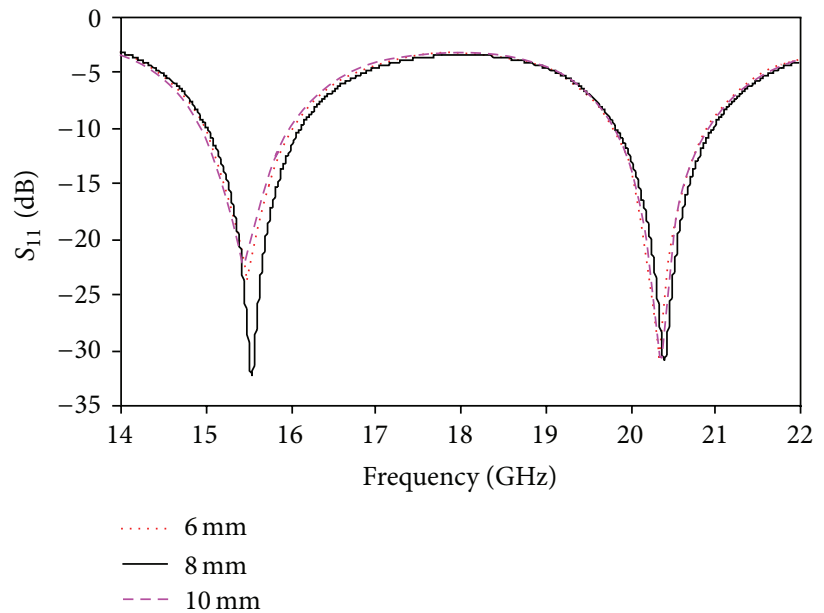

FIgURE 3: Simulated return loss for different values of $L_{1}$.

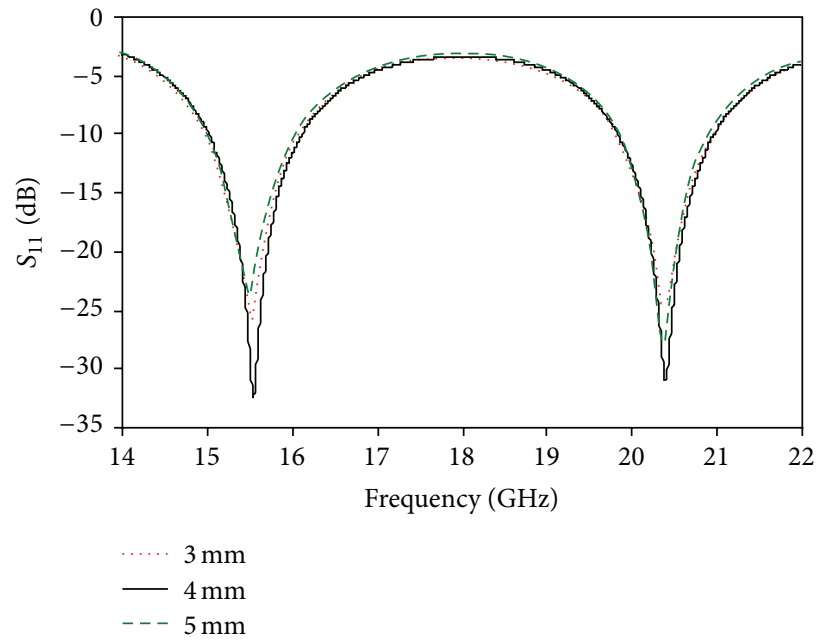

FIGURE 4: Simulated return loss for different values of $W_{1}$.

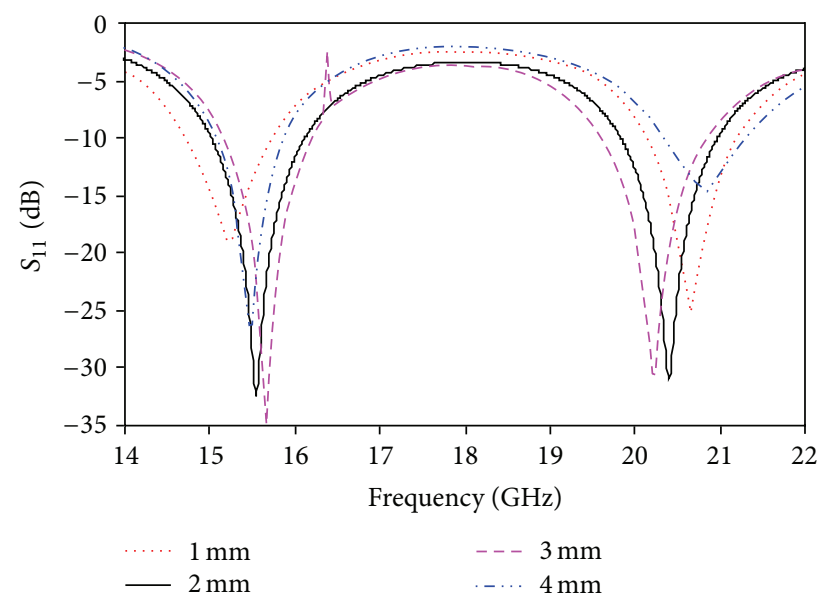

FIGURE 5: Simulated return loss for different values of $R$. 


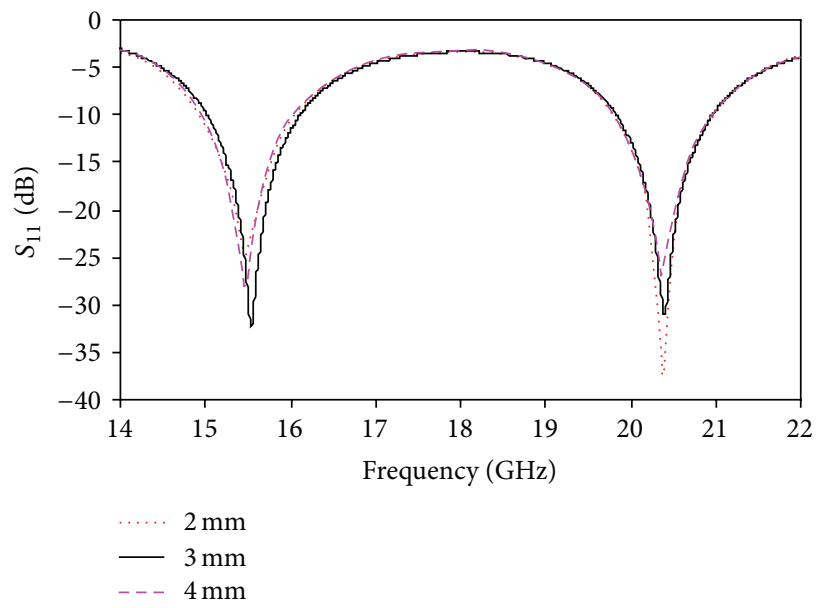

FIgURE 6: Simulated return loss for different values of $W_{2}$.

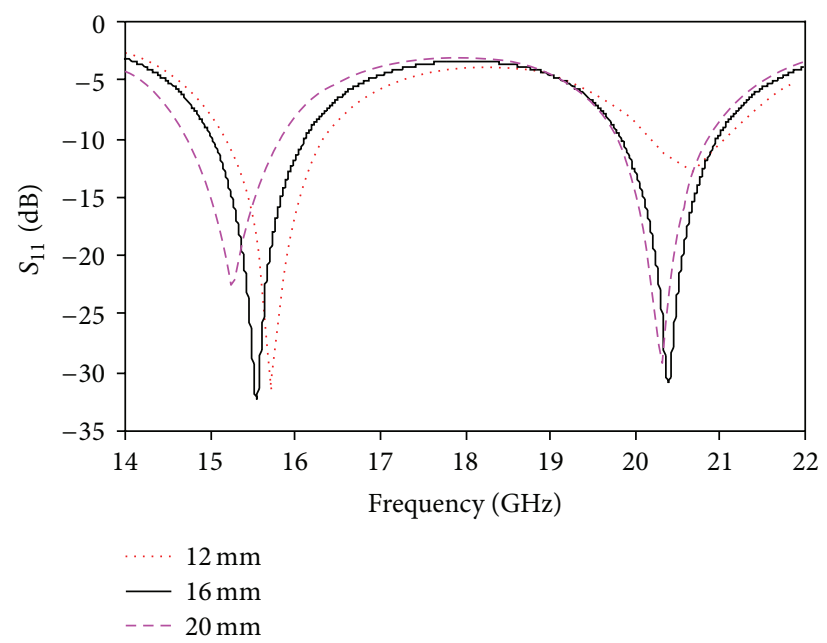

Figure 7: Simulated return loss for different values of $L_{3}$.

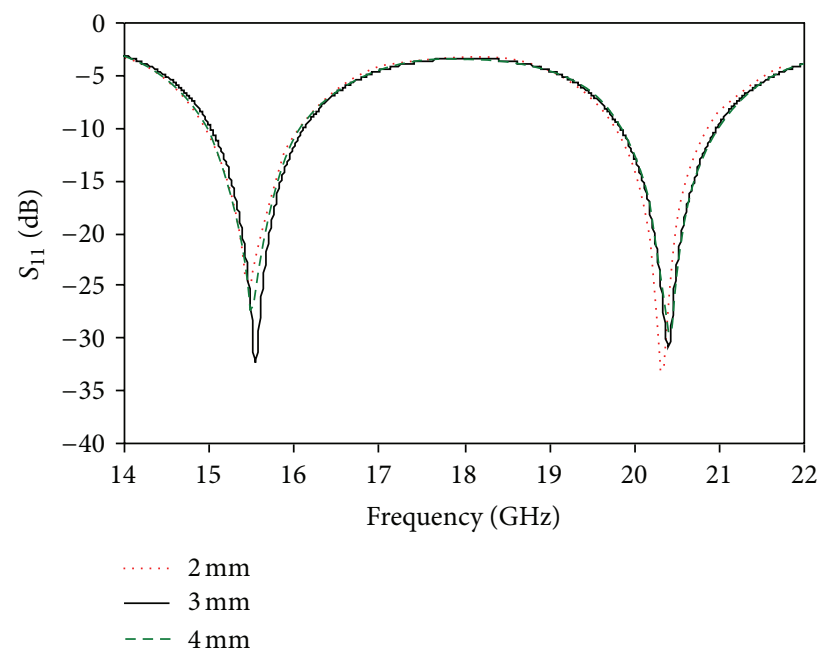

FIgURE 8: Simulated return loss for different values of $W_{3}$. 


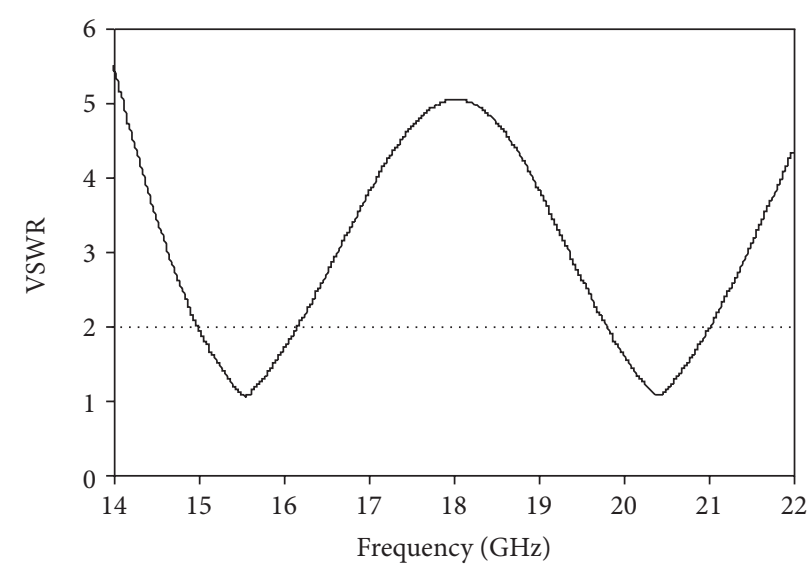

FIGURE 9: VSWR of the proposed antenna.

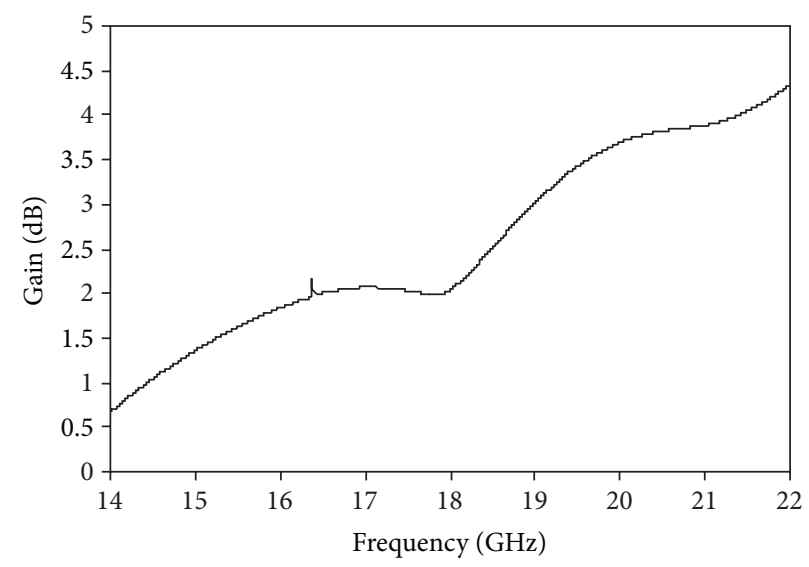

FIGURE 10: Gain of the proposed antenna.

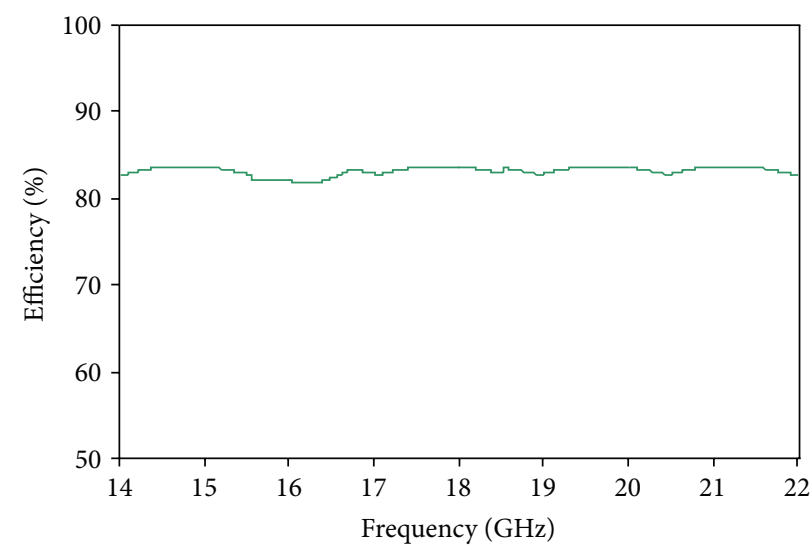

FIGURE 11: Radiation efficiency of the proposed antenna.

The simulated VSWR of the proposed antenna is shown in Figure 9. The standard value of VSWR is less than 2 for the operational bands of the microstrip patch antenna. The value of VSWR achieved is less than 2 in the desired operating bands. The simulated gain of the proposed antenna is shown in Figure 10. The achieved gains are $1.87 \mathrm{~dB}$ on the lower band and $3.87 \mathrm{~dB}$ on the upper band. The radiation efficiency of the proposed antenna is displayed in Figure 11. The $82.80 \%$ efficiency was observed over the entire operating band of Kuand K-band applications.

\section{Experimental Validation}

The anechoic chamber is shown in Figure 12. The proposed antenna measurement was conducted at the Microwave Laboratory, at the Institute of Space Science (ANGKASA), 


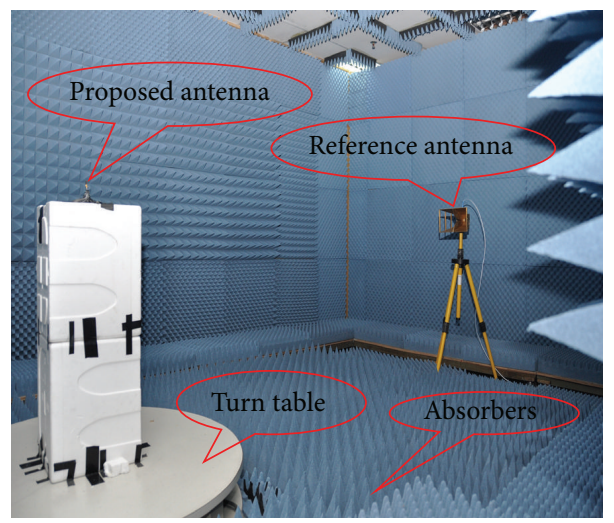

FIGURE 12: Illustration of the anechoic chamber for the proposed antenna.

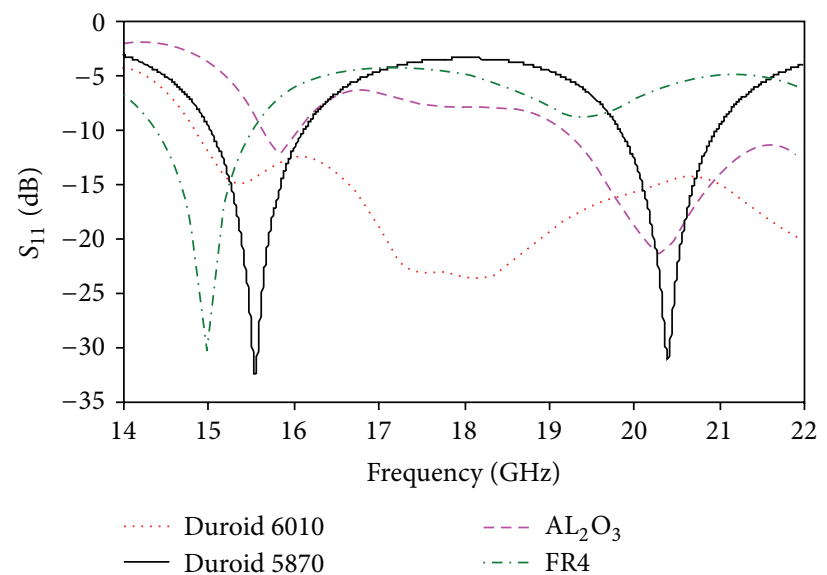

FIGURE 13: Simulated return loss with different substrate materials.

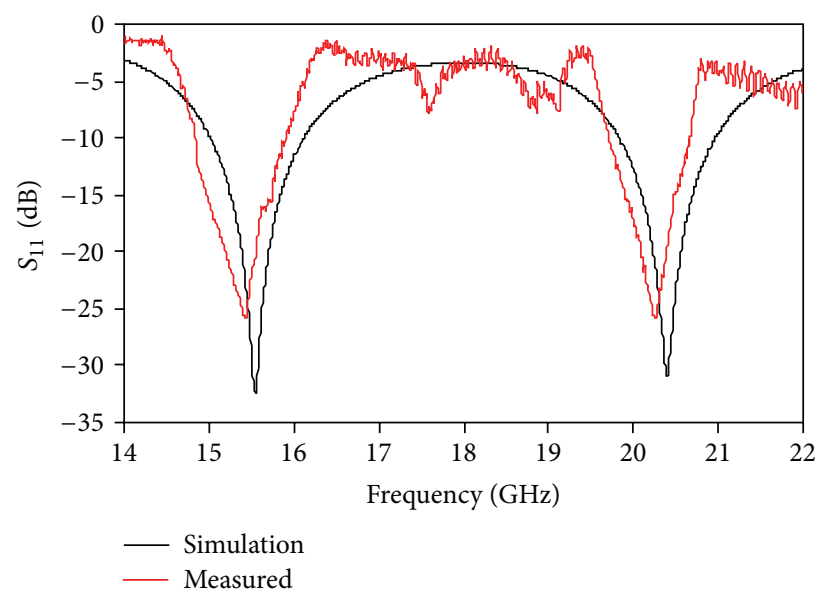

FIGURE 14: Simulated and measured return losses of the proposed antenna.

UKM, Malaysia. The simulated return loss with different substrate materials is shown in Figure 13. When the high permittivity material Duroid 6010 was used as a substrate, a resonance was observed but not desired. Two resonances were found using $\mathrm{AL}_{2} \mathrm{O}_{3}$ ceramic as the substrate material. However, the return losses of these two resonances are very low which is unwanted. When FR4 was used as a substrate, one resonance was found that is not required for dual-band operation. Finally, Duroid 5870 was used in the proposed design, and two strong resonances were achieved with both wide bandwidth and high gain. The simulated and measured return losses of the proposed antenna are shown in Figure 14. 


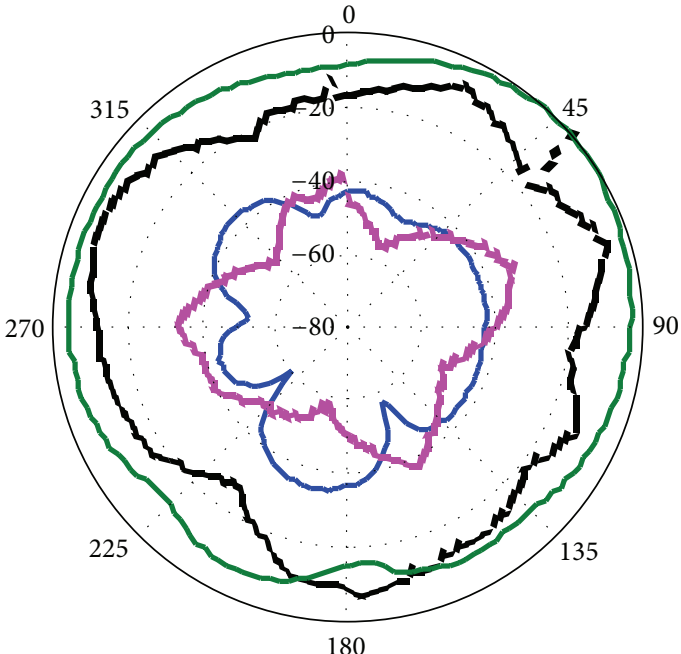

(a)

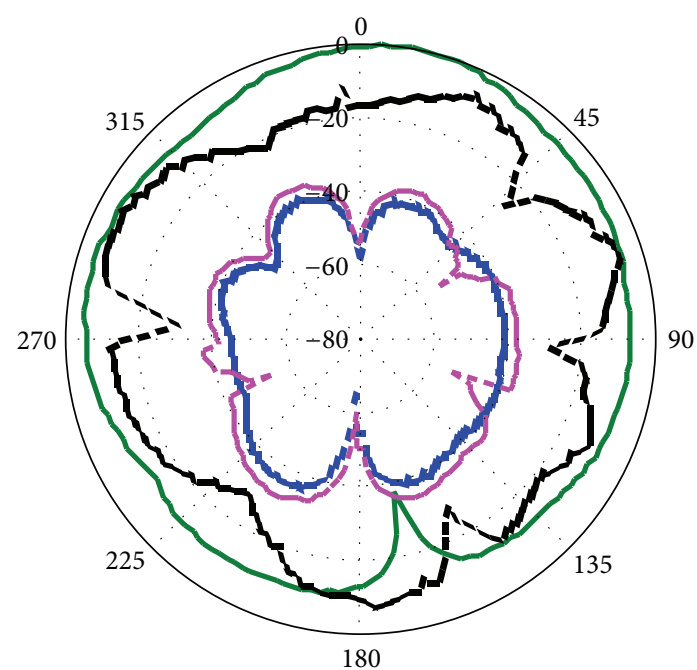

- - - Measured copolar
- - Measured cross-polar
- Simulated copolar
Simulated cross-polar

(c)

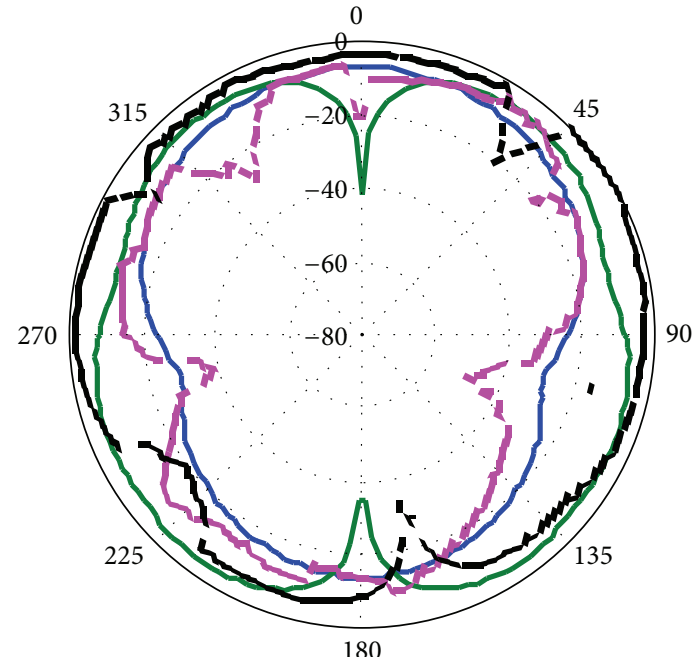

(b)

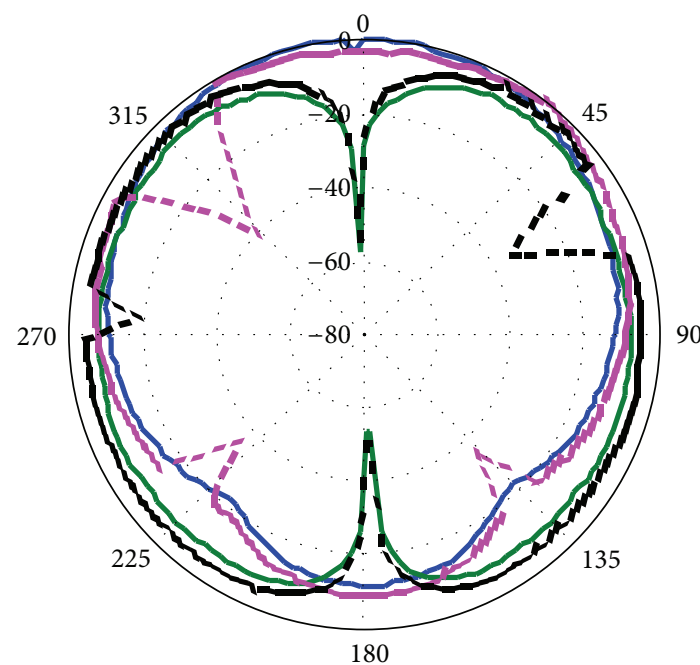

- - - Measured copolar - Simulated copolar
- - Mimulated cross-polar

(d)

FIGURE 15: Measured radiation pattern of the proposed antenna: (a) E-plane at $15.46 \mathrm{GHz}$, (b) H-plane at 15.46 GHz, (c) E-plane at $20.27 \mathrm{GHz}$, (d) H-plane $20.27 \mathrm{GHz}$.

We have achieved a $1.07 \mathrm{GHz}$ bandwidth, ranging from $14.86 \mathrm{GHz}$ to $15.93 \mathrm{GHz}$ on the 1st resonance and $0.94 \mathrm{GHz}$ $(19.73 \mathrm{GHz}-20.67 \mathrm{GHz})$ on the 2 nd resonance, which is validated with measurements. The resonant frequencies are shifted from $15.56 \mathrm{GHz}$ to $15.46 \mathrm{GHz}$ on the lower band and form $20.41 \mathrm{GHz}$ to $20.27 \mathrm{GHz}$ on the upper band.

The measured radiation pattern of the proposed antenna is shown in Figure 15 for (a) E-plane at $15.46 \mathrm{GHz}$, (b) $\mathrm{H}$ plane at $15.46 \mathrm{GHz}$, (c) E-plane at $20.27 \mathrm{GHz}$, and (d) Hplane at $20.27 \mathrm{GHz}$. Two-dimensional (2D) radiation patterns were used to specify co- and cross-polarization at $15.46 \mathrm{GHz}$ and $20.27 \mathrm{GHz}$, respectively. The $E_{\varphi}$ and $E_{\theta}$ fields indicate the cross-polar and copolar components, respectively. The Eplane is considered as the $y$ - $z$ coordinates and the $\mathrm{H}$-plane as the $x-z$ coordinates. It is desired in the case of a standard radiation pattern of a microstrip antenna that the effect of crosspolarisation is lower than that of copolarization. The crosspolarization effect is higher in the 2nd resonant frequency of $20.27 \mathrm{GHz}$. When frequency increases, the effect increases, thereby enabling the simple interpretation from the radiation pattern. From the measurement, nearly omnidirectional and symmetrical radiation patterns were attained along both the E-plane and the H-plane.

The same radiation pattern was observed to exist over the $\mathrm{Ku}-$ and K-bands. The obtained radiation patterns indicate that the proposed antenna delivers linear polarization, for which the level of cross-polarisation is lower than that of copolarisation in all of the simulated radiation patterns. When 


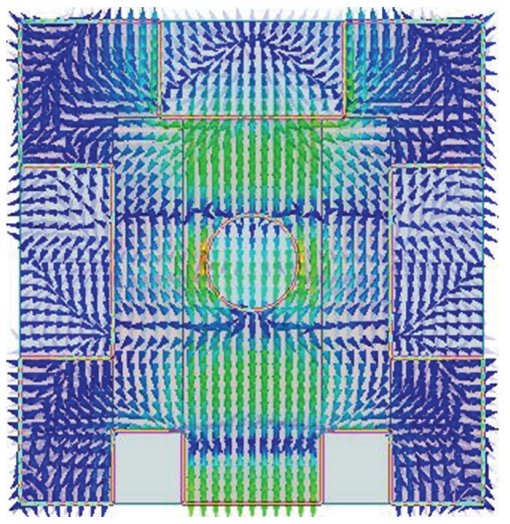

(a)

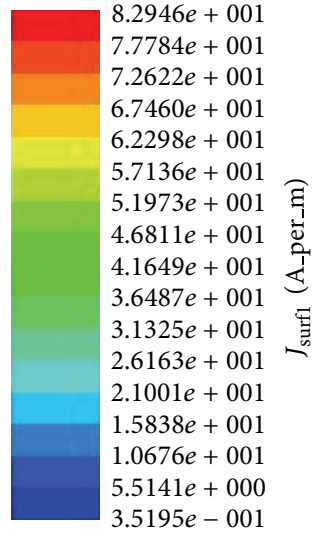

$3.5195 e-001$
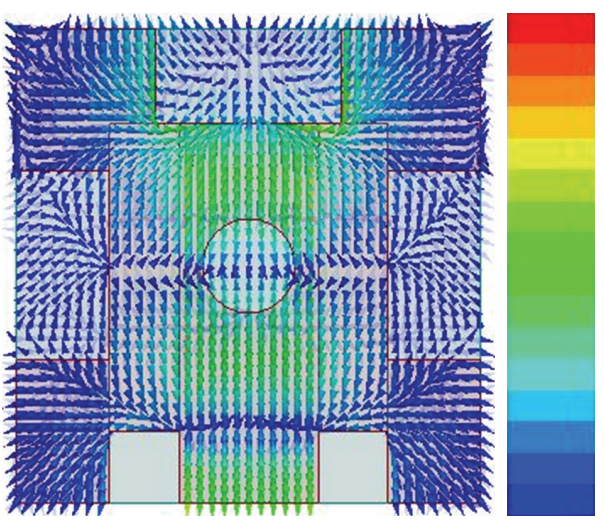

$8.1401 e+001$ $7.6330 e+001$ $7.1259 e+001$ $6.6188 e+001$ $6.1118 e+001$ $5.6047 e+001$ $5.0976 e+001$ ह $4.5905 e+001$ ठั $4.0834 e+001$ से $3.5763 e+001$ $3.0692 e+001$ 車 $2.5621 e+001$ $2.0550 e+001$ $1.5479 e+001$ $1.0408 e+001$ $5.3372 e+000$ $2.6623 e-001$

(b)

FIGURE 16: Current distribution of the proposed antenna at (a) $15.56 \mathrm{GHz}$ and (b) $20.41 \mathrm{GHz}$.

the radiation pattern of a microstrip antenna is symmetric and omni-directional, it provides some reasonable benefits. One benefit is that the resonance does not shift for different directions, so a large amount of stable power is in the direction of the broadside beam. Another advantage is that the radiation pattern is more reliable on the operational bands. The level of cross-polarization at higher frequencies is comparatively higher than that at lower frequencies, which is desired due to the diffractions from the edges of the patch and ground plane. Additionally, the level of this cross-polarisation is observed to be reduced by enhancing the slots on the ground plane; in addition, the radius of the circular slot on the patch is also responsible for this effect. In this way, as will be discussed later, the enhancement of the slots is beneficial. The values of the other parameters are fixed. The results indicate that the radiation patterns are slightly shifted at the higher frequency because the distribution of the nonuniform phase is created on the proposed antenna. These radiation patterns are suitable for Ku- and K-band applications. The dimensions of the patch and the ground plane determine the radiation pattern degradation over the entire $\mathrm{Ku}$ - and $\mathrm{K}$-bands. Thus, the sizes of the patch and the ground plane were selected carefully. If any parameter is changed, the resonant frequency is shifted. As a result, the radiation pattern is also changed from symmetric and omni-directional to bidirectional or another type. Finally, the simulation results are close to measurement results.

Figure 16 shows the current distribution of the proposed antenna for (a) $15.56 \mathrm{GHz}$ and (b) $20.41 \mathrm{GHz}$. A large amount of current flows through the feeding line. The electric field was initiated at this point. The creation of the electric field near the slots is reasonable. As a result, the excitation is strong over all the parts of the antenna for both the lower band and the upper band.

The Smith chart of the proposed antenna is shown in Figure 17. When the dimensions of the patch and the ground plane are changed, the coupling and the input impedance shift for the different resonant loops. The tightest resonant loop is found at the centre of the Smith chart of the proposed

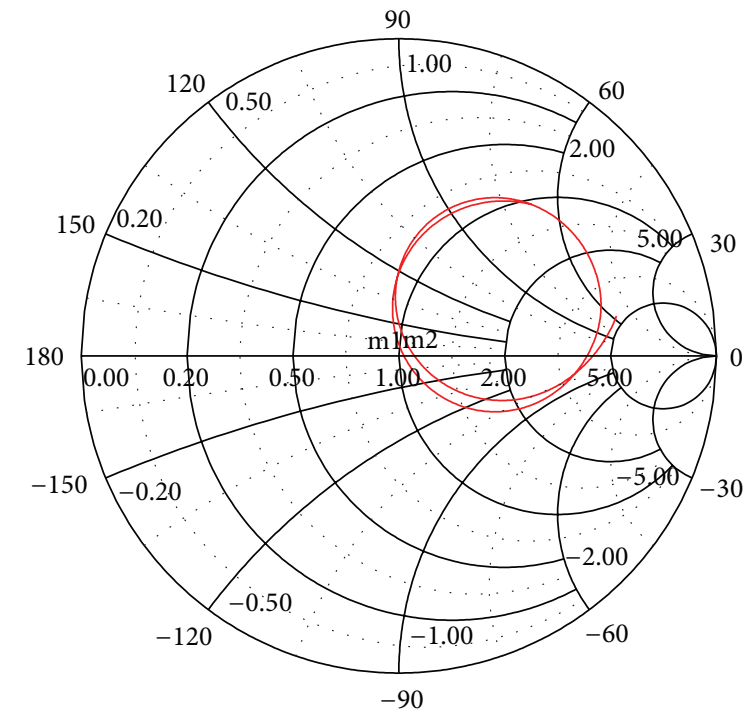

\begin{tabular}{|l|c|c|c|c|}
\hline Name & Freq & Ang & Mag & RX \\
\hline $\mathrm{m} 1$ & 15.5600 & 31.0377 & 0.0235 & $1.0409+0.0253 i$ \\
\hline $\mathrm{m} 2$ & 20.4100 & 24.1932 & 0.0277 & $1.0516+0.0239 i$ \\
\hline
\end{tabular}

FIGURE 17: The Smith chart of the proposed antenna.

antenna design. This resonance loop indicates the improved bandwidth of the proposed antenna.

\section{Conclusion}

The proposed design and characterization of a prototype of a microstrip antenna with dual-band operation on a substrate of Duroid 5870 material to cover Ku- and K-band applications were described. The $10 \mathrm{~dB}$ bandwidth of $1.07 \mathrm{GHz}$ in the 1st resonance at $15.46 \mathrm{GHz}$ and of $0.94 \mathrm{GHz}$ in the 2nd resonance at $20.27 \mathrm{GHz}$ were found, which satisfies the conditions of any $\mathrm{Ku}$ - and K-band application. Good agreement between the simulation and measured results was observed. Attractive 
radiation patterns, low cross-polarization, and efficiency with improved bandwidth and higher gain make the proposed antenna compatible for use in $\mathrm{Ku}$ - and $\mathrm{K}$-band applications.

\section{References}

[1] L. H. Weng, Y. C. Guo, X. W. Shi, and X. Q. Chen, "An overview on defected ground structure," Progress in Electromagnetics Research B, vol. 7, pp. 173-189, 2008.

[2] W.-C. Liu and C.-F. Hsu, "Dual-band CPW-fed Y-shaped monopole antenna for PCS/WLAN application," Electronics Letters, vol. 41, no. 7, pp. 390-391, 2005.

[3] C.-M. Wu, "Dual-band CPW-fed cross-slot monopole antenna for WLAN operation," IET Microwaves, Antennas and Propagation, vol. 1, no. 2, pp. 542-546, 2007.

[4] G. Augustin, S. V. Shynu, P. Mohanan, C. K. Aanandan, and K. Vasudevan, "Compact dual-band antenna for wireless access point," Electronics Letters, vol. 42, no. 9, pp. 502-503, 2006.

[5] C. P. Hsieh, T. C. Chiu, and C. H. Lai, "Compact dual-band slot antenna at the corner of the ground plane," IEEE Transactions on Antennas and Propagation, vol. 57, no. 10, pp. 3423-3426, 2009.

[6] W.-C. Liu, C.-M. Wu, and N.-C. Chu, "A compact CPW-Fed slotted patch antenna for dual-band operation," IEEE Antennas and Wireless Propagation Letters, vol. 9, pp. 110-113, 2010.

[7] M. T. Islam, M. R. I. Faruque, and N. Misran, "Specific absorption rate analysis using metal attachment," Informacije MIDEM, vol. 40, no. 3, pp. 238-240, 2010.

[8] M. T. Islam, M. R. I. Faruque, and N. Misran, "SAR reduction in a muscle cube with metamaterial attachment," Applied Physics A, vol. 103, no. 2, pp. 367-372, 2011.

[9] M. T. Islam, M. R. I. Faruque, and N. Misran, "Evaluation of EM absorption in human head with metamaterial attachment," Applied Computational Electromagnetics Society Journal, vol. 25, no. 12, pp. 1097-1107, 2010.

[10] M. R. I. Faruque, M. T. Islam, and N. Misran, "Design analysis of new metamaterial for EM absorption reduction," Progress in Electromagnetics Research, vol. 124, pp. 119-135, 2012.

[11] M. T. Islam, H. Z. Abidin, M. R. I. Faruque, and N. Misran, "Analysis of materials effects on radio frequency electromagnetic fields in human head," Progress in Electromagnetic Research, vol. 128, pp. 121-138, 2012.

[12] M. R. I. Faruque, M. T. Islam, and N. Misran, "Electromagnetic (EM) absorption reduction in a muscle cube with metamaterial attachment," Medical Engineering and Physics, vol. 33, no. 5, pp. 646-652, 2011.

[13] M. T. Islam, M. R. I. Faruque, and N. Misran, "Study of specific absorption rate (SAR) in the human head by metamaterial attachment," IEICE Electronics Express, vol. 7, no. 4, pp. 240246, 2010.

[14] M. R. I. Faruque, M. T. Islam, and N. Misran, "Effect of human head shapes for mobile phone exposure on electromagnetic absorption," Informacije MIDEM, vol. 40, no. 3, pp. 232-237, 2010.

[15] R. Azim, M. T. Islam, and N. Misran, "Dual polarized microstrip patch antenna for Ku-band application," Informacije MIDEM, vol. 41, no. 2, pp. 114-117, 2011.

[16] M. H. Ullah, M. T. Islam, J. S. Mandeep, and N. Misran, "Design and analysis of a multi band electrically small antenna using ceramic material substrate," Przeglad Elektrotechniczny, vol. 89, no. 1, pp. 271-274, 2013.
[17] S. K. Dubey, S. K. Pathak, and K. K. Modh, "High gain multiple resonance Ku-band microstrip patch antenna," in Proceedings of the IEEE Applied Electromagnetics Conference, pp. 1-3, Kolkata, India, December 2011.

[18] N. Misran, M. T. Islam, N. M. Yusob, and A. T. Mobashsher, "Design of a compact dual band microstrip antenna for ku-band application," in Proceedings of the International Conference on Electrical Engineering and Informatics (ICEEI '09), vol. 2, pp. 699-702, Selangor, Malaysia, August 2009.

[19] M. Samsuzzaman, M. T. Islam, B. Yatim, and M. A. M. Ali, "Dual frequency triangular slotted microstrip patch antenna for $\mathrm{Ku}$ band applications," Przegląd Elektrotechniczny, vol. 89, no. 1, pp. 275-279, 2013.

[20] Y.-L. Kuo and K.-L. Wong, "Printed double-T monopole antenna for 2.4/5.2 Ghz dual-band WLAN operations," IEEE Transactions on Antennas and Propagation, vol. 51, no. 9, pp. 2187-2192, 2003.

[21] M. T. Islam, N. Misran, and A. T. Mobashsher, "Compact dual band microstrip antenna for Ku-band application," Information Technology Journal, vol. 9, no. 2, pp. 354-358, 2010.

[22] C.-C. Lin, G.-Y. Lee, and K.-L. Wong, "Surface-mount dualloop antenna for $2.4 / 5 \mathrm{GHz}$ WLAN operation," Electronics Letters, vol. 39, no. 18, pp. 1302-1304, 2003.

[23] D. Nashaat, H. A. Elsadek, and H. Ghali, "Dual-band reduced size PIFA antenna with U-slot for Bluetooth and WLAN applications," in Proceedings of the IEEE International Antennas and Propagation Symposium and USNC/CNC/URSI North American Radio Science Meeting, vol. 2, pp. 962-967, Columbus, Ohio, USA, June 2003.

[24] Y.-H. Suh and K. Chang, "Low cost microstrip-fed dual frequency printed dipole antenna for wireless communications," Electronics Letters, vol. 36, no. 14, pp. 1177-1179, 2000.

[25] C.-M. Su, H.-T. Chen, and K.-L. Wong, "Printed dual-band dipole antenna with U-slotted arms for $2.4 / 5.2 \mathrm{GHz}$ WLAN operation," Electronics Letters, vol. 38, no. 22, pp. 1308-1309, 2002.

[26] J.-W. Wu, H.-M. Hsiao, J.-H. Lu, and S.-H. Chang, "Dual broadband design of rectangular slot antenna for 2.4 and $5 \mathrm{GHz}$ wireless communication," Electronics Letters, vol. 40, no. 23, pp. 1461-1463, 2004.

[27] Z. Zhang, M. F. Iskander, J.-C. Langer, and J. Mathews, "Dualband WLAN dipole antenna using an internal matching circuit," IEEE Transactions on Antennas and Propagation, vol. 53, no. 5, pp. 1813-1818, 2005.

[28] I. J. Bahl and P. Bhartia, Microstrip Antennas, Artech House, Boston, Mass, USA, 2nd edition, 1980. 

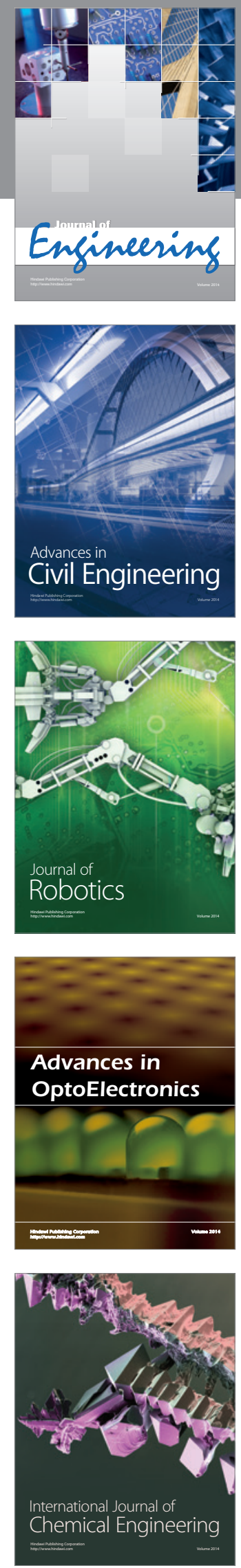

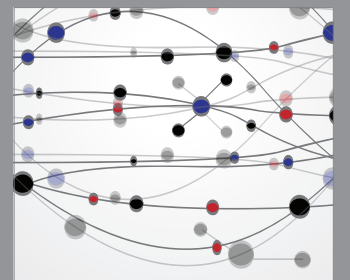

The Scientific World Journal
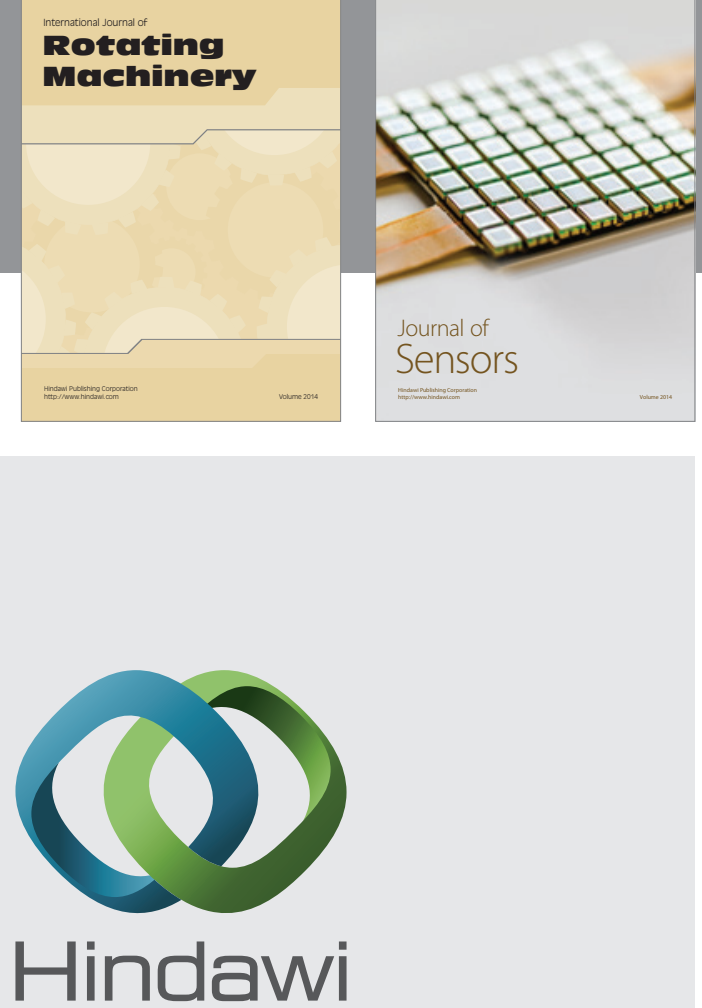

Submit your manuscripts at http://www.hindawi.com
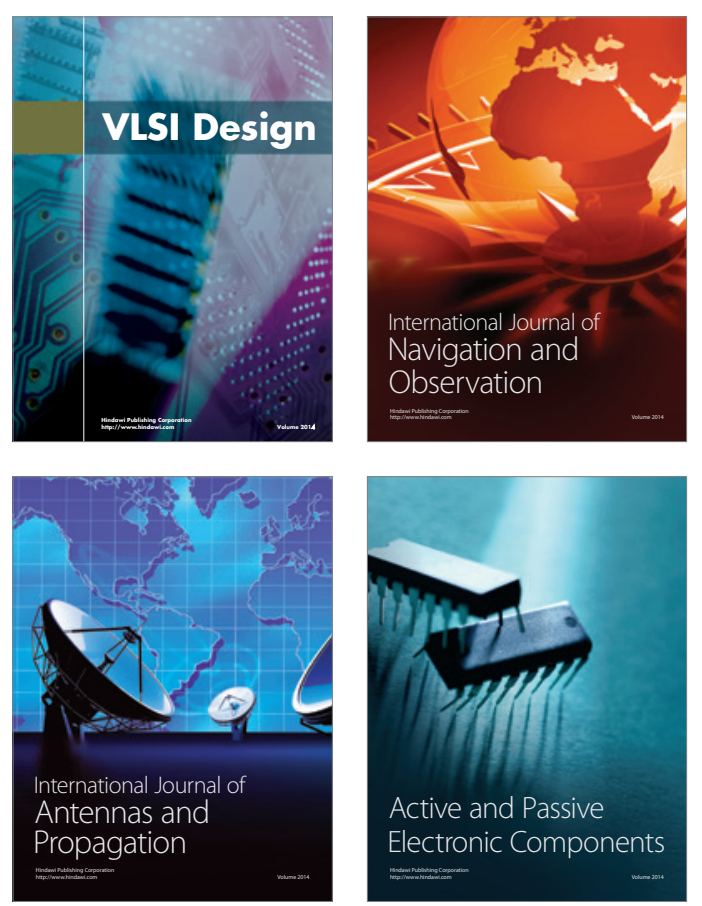
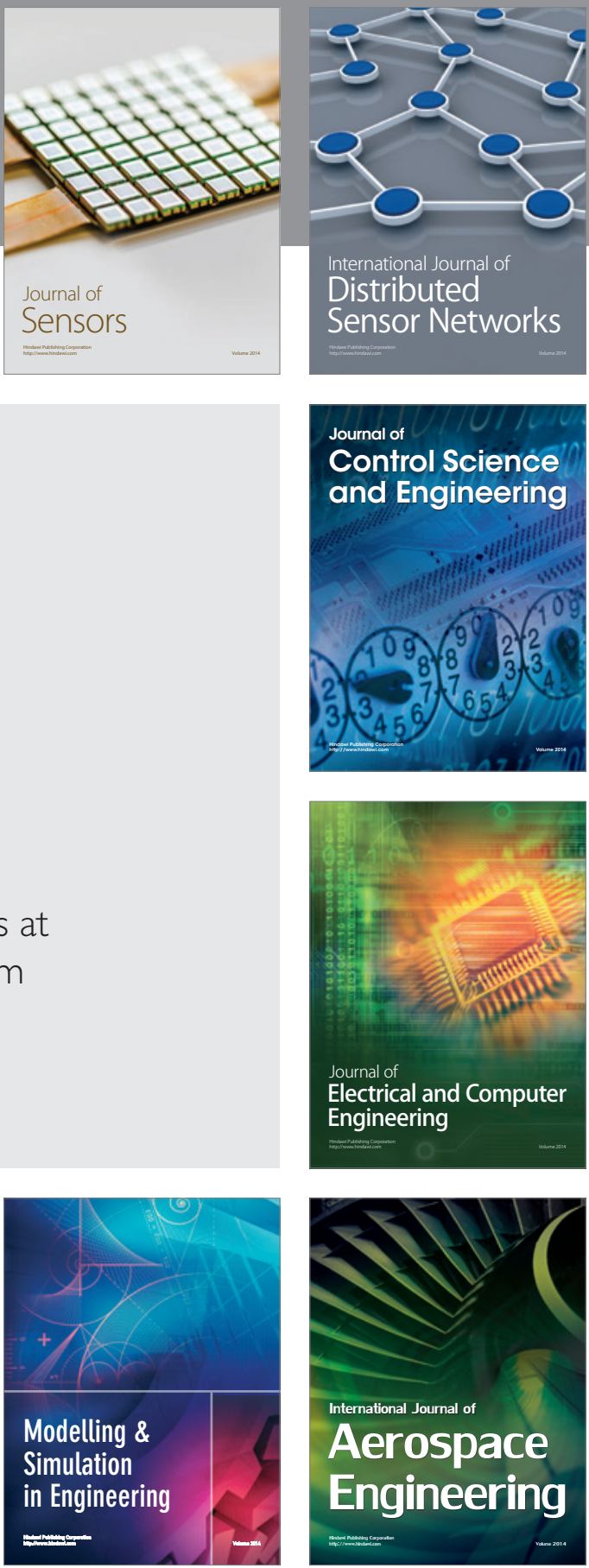

Journal of

Control Science

and Engineering
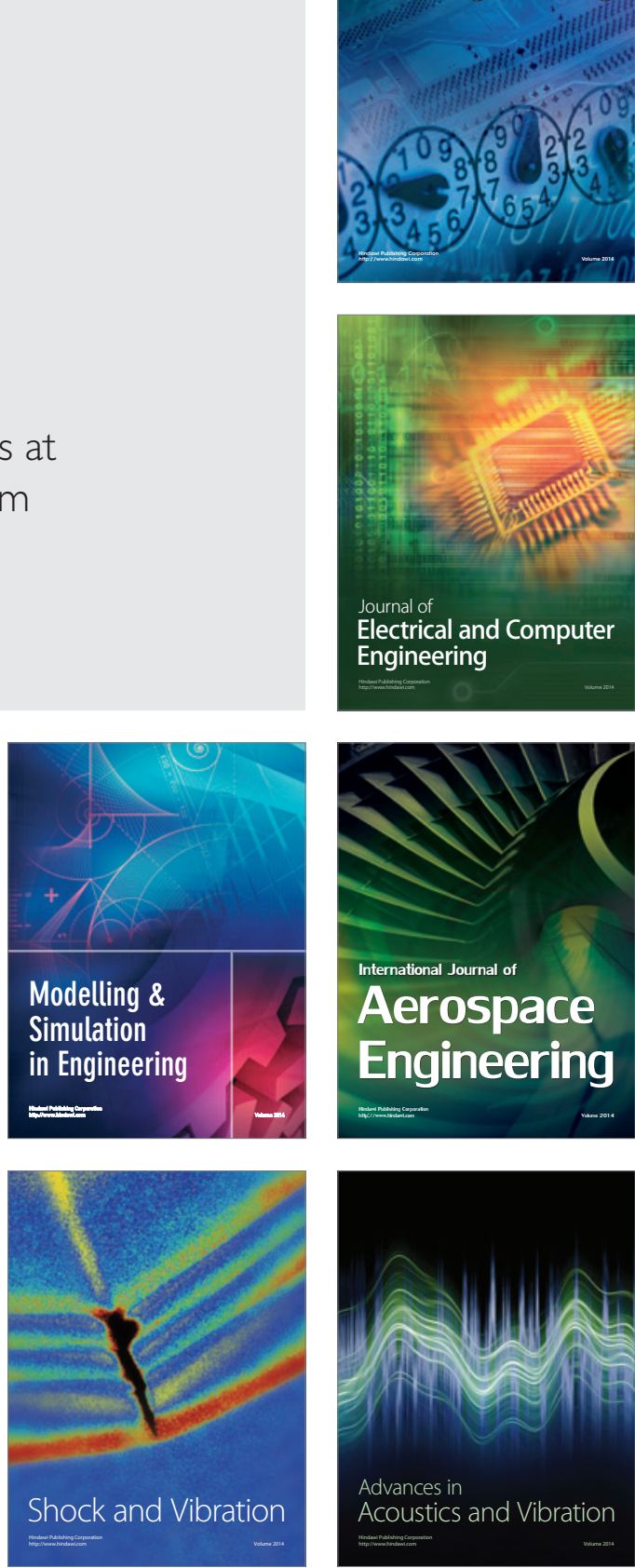